2001

\title{
Twenty-Five Years of Population Fluctuations of Microtus Ochrogaster and M-Pennsylvanicus in Three Habitats in East-Central Illinois
}

Lowell L. Getz

Joyce E. Hofmann

Betty McGuire

Old Dominion University

Thomas W. Dolan III

Old Dominion University

Follow this and additional works at: https://digitalcommons.odu.edu/biology_fac_pubs

Part of the Ecology and Evolutionary Biology Commons, and the Zoology Commons

\section{Repository Citation}

Getz, Lowell L.; Hofmann, Joyce E.; McGuire, Betty; and Dolan, Thomas W. III, "Twenty-Five Years of Population Fluctuations of Microtus Ochrogaster and M-Pennsylvanicus in Three Habitats in East-Central Illinois" (2001). Biological Sciences Faculty Publications. 349.

https://digitalcommons.odu.edu/biology_fac_pubs/349

\section{Original Publication Citation}

Getz, L. L., Hofmann, J. E., McGuire, B., \& Dolan, T. W. (2001). Twenty-five years of population fluctuations of microtus ochrogaster and m-pennsylvanicus in three habitats in East-Central Illinois. Journal of Mammalogy, 82(1), 22-34. doi:10.1644/

1545-1542(2001)082<0022:tfyopf>2.0.co;2 


\title{
TWENTY-FIVE YEARS OF POPULATION FLUCTUATIONS OF MICROTUS OCHROGASTER AND M. PENNSYLVANICUS IN THREE HABITATS IN EAST-CENTRAL ILLINOIS
}

\author{
Lowell L. Getz,* Joyce E. Hofmann, Betty McGuire, and Thomas W. Dolan III \\ Department of Ecology, Ethology, and Evolution, University of Illinois, \\ 505 South Goodwin Avenue, Urbana, IL 61801 (LLG) \\ Illinois Natural History Survey, 607 East Peabody Drive, Champaign, IL 81820 (JEH) \\ Department of Biological Sciences, Smith College, Northampton, MA 01063 (BM) \\ Department of Biological Sciences, Old Dominion University, Norfolk, VA 23529 (TWD)
}

Populations of 2 species of arvicoline rodents, the prairie vole (Microtus ochrogaster) and meadow vole (M. pennsylvanicus), were monitored monthly in alfalfa, bluegrass, and tallgrass prairie habitats in east-central Illinois from 1972 through 1997. Alfalfa provides very highquality preferred food and poor vegetative cover for both vole species, whereas bluegrass provides intermediate food and vegetative cover. Preferred food resources were very low, especially for $M$. ochrogaster, and vegetative cover was very dense in tallgrass prairie. Maximum and mean population densities of $M$. ochrogaster were highest in alfalfa, intermediate in bluegrass, and lowest in tallgrass prairie. Populations of M. ochrogaster displayed synchronous 3- to 4-year multiannual cycles in all 3 habitats. Cycles were most pronounced in alfalfa, less pronounced in bluegrass, and barely discernible in tallgrass prairie. Food availability seems more important than vegetative cover for the success of $M$. ochrogaster. Densities of $M$. pennsylvanicus generally were very low in bluegrass and alfalfa habitats, both of which contained an abundance of preferred food plants. When M. pennsylvanicus was present in abundance in these 2 habitats, populations displayed annual or erratic fluctuations. Densities of $M$. pennsylvanicus were much higher in tallgrass prairie than in the other 2 habitats. Although vegetative cover seems more important than food availability for the success of $M$. pennsylvanicus, no evidence existed for population cycles in tallgrass prairie. We found no synchrony among population fluctuations of the 2 species of voles in the 3 habitats.

Key words: meadow voles, Microtus ochrogaster, Microtus pennsylvanicus, population cycles, prairie voles

Many species of arvicoline (microtine) rodents undergo high-amplitude fluctuations in numbers. Many populations fluctuate erratically, but some fluctuations clearly are annual events, and others represent multiannual "population cycles" with peak densities typically occurring at 3- to 4-year intervals (Krebs and Myers 1974; Taitt and Krebs 1985). Intellectual curiosity evoked by the apparent cyclicity of populations has resulted in a plethora

*Correspondent: l-getz@life.uiuc.edu of field studies and publications over the past several decades. This vast research effort has produced considerable evidence regarding factors that may be involved in changes in population density. In excess of 22 hypotheses have been proposed to explain cyclic phenomena in arvicoline rodents (Batzli 1992, 1996). However, no consensus has yet been reached as to causative factors that are applicable to different populations of a given species or populations of different species (Batzli 1996). 
Considerable variation has been observed in the configuration of population fluctuations among species and among populations of the same species (Bjornstad et al. 1998; Krebs and Myers 1974; Saitoh et al. 1998). Site-specific (habitat), temporal, and geographic differences have been recorded. Within a species, populations occupying different habitats in the same region may display erratic, annual, or multiannual fluctuations (Taitt and Krebs 1985). Populations of a species at a given site may display annual fluctuations at some times and multiannual cycles at other times (Marcstrom et al. 1990). Species with similar habitat requirements may display different cyclic phenomena, and species with different requirements may display similar cycles in the same site (Getz et al. 1987; Krebs et al. 1969; Marcstrom et al. 1990; Taitt and Krebs 1985). It is small wonder that simple explanations of population fluctuations of arvicoline rodents have been elusive.

A major problem inherent in arriving at a coherent explanation of population cycles is the need for long-term data. Average duration of studies for the 106 total years of data cited by Taitt and Krebs (1985) was just over 3.5 years. The longest study was 13 years, another was 11 years, and 2 each were 7 years in duration. Several more extensive data sets, some ranging up to 52 years, have been described recently (Agrell et al. 1992; Getz and Hofmann 1999; Marcstrom et al. 1990; Saitoh et al. 1998). However, those very long-term data sets resulted from infrequent trapping (often only $\leq 3$ sessions/year), typically during late spring, summer, or early autumn. Most came from snap-trapping or pit-fall sampling. Some obvious shortcomings are associated with such data. When only a few trapping sessions per year are conducted, the actual peak density may be missed because populations do not peak at the same time during different years or among sites during the same year (Getz et al. 1987). Demographic events during other seasons that may provide explanations of cyclic phenomena may be missed. Further, limited trapping does not allow analyses of the role of changes in survival, reproduction, sex ratio, and other demographic traits in generating annual or multiannual population cycles.

Our study compensated for some of those problems. Study sites were established in 3 distinct habitats located within a radius of $500 \mathrm{~m}$. Two species of voles, the prairie vole (Microtus ochrogaster) and meadow vole (M. pennsylvanicus), inhabited the 3 habitats. Monthly live-trapping sessions were conducted in all 3 habitats throughout the year for 25 years, 1972-1997.

We described types of population fluctuations displayed by the 2 species in the 3 habitats and the degree of synchrony among populations of each species and between the 2 species. We also compared population densities of each species among the 3 habitats.

\section{Materials AND Methods}

Study sites.-The study sites were located in the University of Illinois Biological Research Area (Phillips Tract) and Trelease Prairie, both $6 \mathrm{~km} \mathrm{NE}$ of Urbana, Illinois $\left(40^{\circ} 15^{\prime} \mathrm{N}\right.$, $\left.88^{\circ} 28^{\prime} \mathrm{W}\right)$. Populations of $M$. ochrogaster and M. pennsylvanicus were monitored in 3 distinct habitats: restored tallgrass prairie (March 1972 May 1997), bluegrass (Poa pratensis; January 1972-May 1997), and alfalfa (Medicago sativa; May 1972-May 1997). Tallgrass prairie was the original habitat of both species in Illinois, and bluegrass, an introduced species, represents 1 of the more common habitats in which the 2 species can be found today in Illinois. Alfalfa is an atypical habitat that provides exceptionally highquality food for both species (Cole and Batzli 1979; Lindroth and Batzli 1984).

A number of manipulative studies were conducted during the course of the 25-year demographic study (Getz et al. 1987). Those studies examined effects of supplemental feeding and interspecific competition, and some involved removal of 1 species. Data presented in this paper are from unmanipulated sites in which both species were present. M. pennsylvanicus did not occur in the study region before 1972 (Getz et al. 


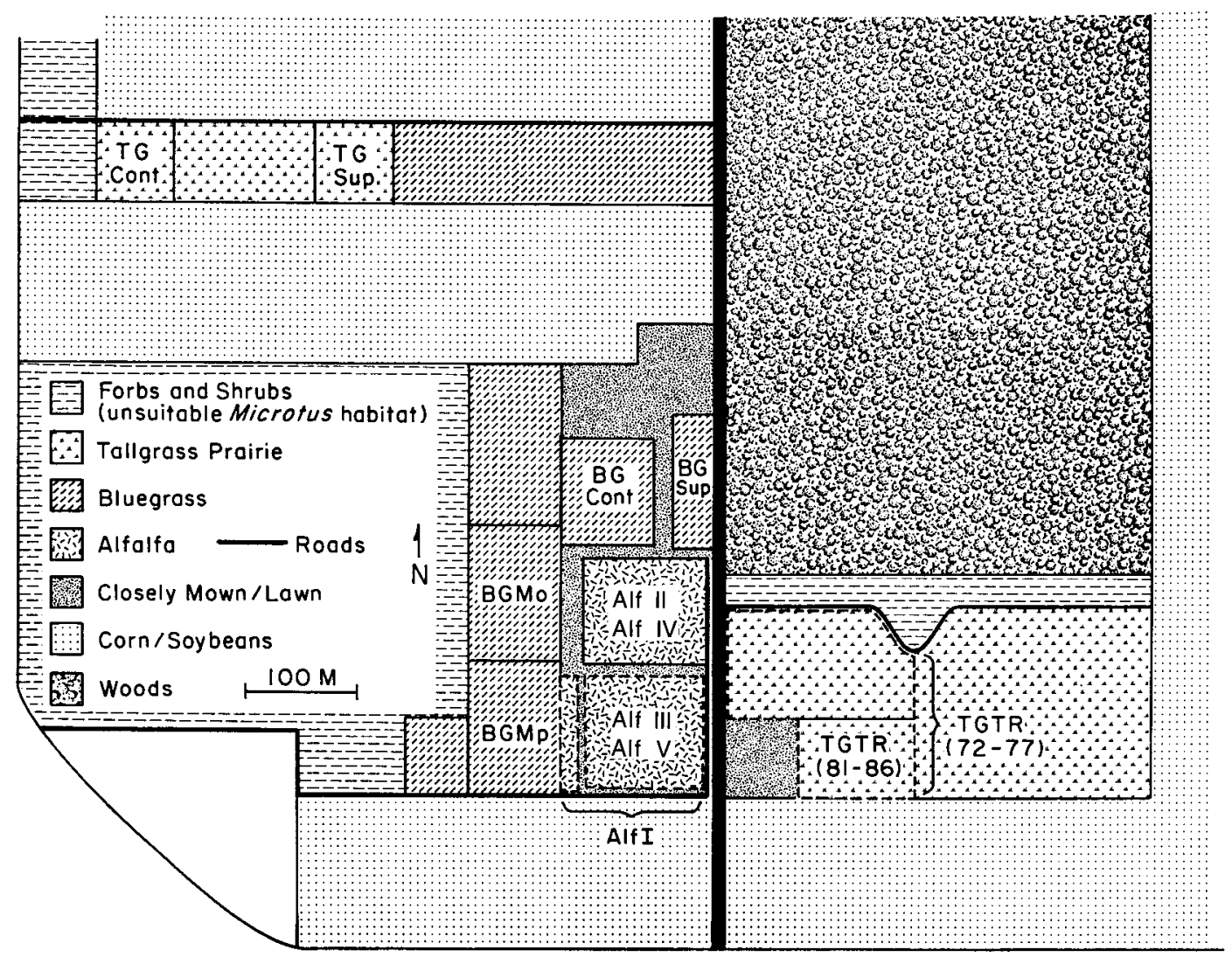

FIG. 1.-Location of the study sites in Phillips Tract and Trelease Prairie (west and east of the road, respectively); see Table 1 for site indicators and area of each. TG $=$ tallgrass, $\mathrm{BG}=$ bluegrass, Alf $=$ alfalfa, Cont $=$ control, Sup $=$ supplemental fed, $\mathrm{Mo}=M$. ochrogaster, $\mathrm{Mp}=M$. pennsylvanicus, and TR = Trelease Prairie.

1978); the species 1st appeared in the study sites in May 1973.

We trapped at 2 restored tallgrass prairies, 1 located in Trelease Prairie and the other in Phillips Tract (Fig. 1; Table 1). Trelease Prairie, established in 1944, was bordered by a mowed lawn, cultivated fields, forbs and shrubs, and a macadam county road. In 1980, the cultivated field to the south of the study site (Fig. 1) was converted to grazed pasture. Relative abundances of plants (based on dry weight of vegetation clipped at the surface of 26 randomly located $0.25-\mathrm{m}^{2}$ plots) in Trelease Prairie were: big bluestem (Andropogon gerardii; 17\%), bush clover (Lespedeza cuneata; 16\%), ironweed (Veronia; $12 \%)$, Indian grass (Sorghastrum nutans; 10\%), milkweed (Asclepias; 9\%), goldenrod (Solidago; 9\%), bluegrass (5\%), switch grass (Panicum; $5 \%$ ), blackberry (Rubus; 2\%), little bluestem
(Andropogon scoparius; 2\%), and about 10 other species with relative abundances of $<1 \%$ (Getz et al. 1979).

The tallgrass prairie in the Phillips Tract was established in 1968. That site was bordered on 1 side by an abandoned field that underwent succession from forbs and grasses to shrubs and small trees by the time the study ended. Cultivated fields bordered the other 3 sides. When trapping was 1 st conducted at the Phillips Tract site in September 1977, prairie vegetation was well developed. Lindroth and Batzli (1984) recorded relative abundances of the most prominent plant species in that site: A. gerardii (38\%), L. cuneata $(25 \%)$, Beard tongue foxglove (Penstemon digitalis; $16 \%)$, and S. nutans (19\%). All other species represented $<1 \%$ relative abundance. Both prairies were burned during the spring at 3- to 4-year intervals to retard invading 
TABLE 1.-Study sites and duration of trapping; both Microtus species were present in all sites. ${ }^{a}$

\begin{tabular}{lll}
\hline \multicolumn{1}{c}{ Sites } & Area (ha) & \multicolumn{1}{c}{ Dates trapped } \\
\hline Alfalfa & & \\
Alf I & 1.4 & May 1972-March 1977 \\
Alf II & 1.0 & March 1977-July 1984 \\
Alf III & 1.0 & October 1983-December 1989 \\
Alf IV & 1.0 & January 1990-June 1993 \\
Alf V & 1.0 & July 1993-May 1997 \\
Bluegrass & & \\
BG Mo and BG Mp & 2.0 & January 1972-February 1977 \\
BG Cont & 0.8 & March 1977-May 1987 \\
BG Mp & 1.0 & June 1987-May 1997 \\
Tallgrass & & \\
TG TR & 2.0 & March 1972-March 1977 \\
TG Cont & 0.5 & September 1977-May 1984 \\
TG TR & 0.7 & September 1984-May 1987 \\
TG Sup & 0.5 & September 1987-May 1997 \\
\hline
\end{tabular}

a See Fig. 1 for location of sites.

shrubs and trees (Figs. 2 and 4). We trapped at 1 or the other of the 2 tallgrass prairie study areas, depending upon requirements of the overall study at the time (Table 1). Vole populations fluctuated in synchrony in the 2 tallgrass areas (L. L. Getz, in litt.).

The bluegrass study sites were established within a former bluegrass pasture located in Phillips Tract (Fig. 1; Table 1). The pasture was released from grazing in June 1971; dense vegetative cover existed by autumn 1971. Relative abundances of plants (same methods as in Trelease Prairie) during that period were: bluegrass (70\%), dandelion (Taraxacum officinale; 14\%), wild parsnip (Pastinaca sativa; 4\%), goatsbeard (Tragopogon; 3\%), and about 20 other species with relative abundances of $\leq 1 \%$ (Getz et al. 1979).

To reduce successional changes, especially of invading forbs, shrubs, and trees, bluegrass sites were mowed during late summer every 2-3 years. The entire area was mowed at the same time. The rotary mower was set to cut the vegetation about $25 \mathrm{~cm}$ above the surface. That height resulted in suppression of growth of the invading forbs and woody vegetation but left the bluegrass uncut. Vegetation in this site remained relatively unchanged throughout the first 22 years of the study. During the last 3 years of the study, brome grass (Bromus inermis) rapidly became established throughout the study site, comprising nearly $75 \%$ of the vegetation. Timothy
(Phleum pratense) also became prominent in parts of the study site at this time, and bluegrass made up about $20 \%$ of the ground cover.

Trapping was conducted a 2 sites with alfalfa during the study (Fig. 1; Table 1). Trapping was conducted at a site until the alfalfa began to be crowded out by invading forbs and grasses. One year before trapping was terminated in 1 site, the other was planted to alfalfa so that the alfalfa would be fully developed when trapping commenced in that site. Sites were separated by a 10-m closely mown strip. This strip reduced the incidence of animals whose nests were in 1 field having home ranges extending into the other field during the period when alfalfa was present in both sites. However, animals moved between the 2 sites, so we presumed we were monitoring a single population. Initially, alfalfa comprised $75 \%$ of the vegetation in each site. During the last year of usage, common plants (in addition to alfalfa) included bluegrass, goldenrod, timothy, brome grass, clover (Trifolium repens and T. pratense), and plantain (Plantago). A series of 3-m-wide strips were mowed $25 \mathrm{~cm}$ above the surface periodically each summer to control invading weedy forbs and promote new growth of alfalfa plants. The 1st strips usually were mowed in early June; mowing normally stopped in mid-September. The subsequent strips were not mowed until vegetation in the previously mowed strips was nearly full-grown. Times of mowing were spaced so that at least two-thirds 

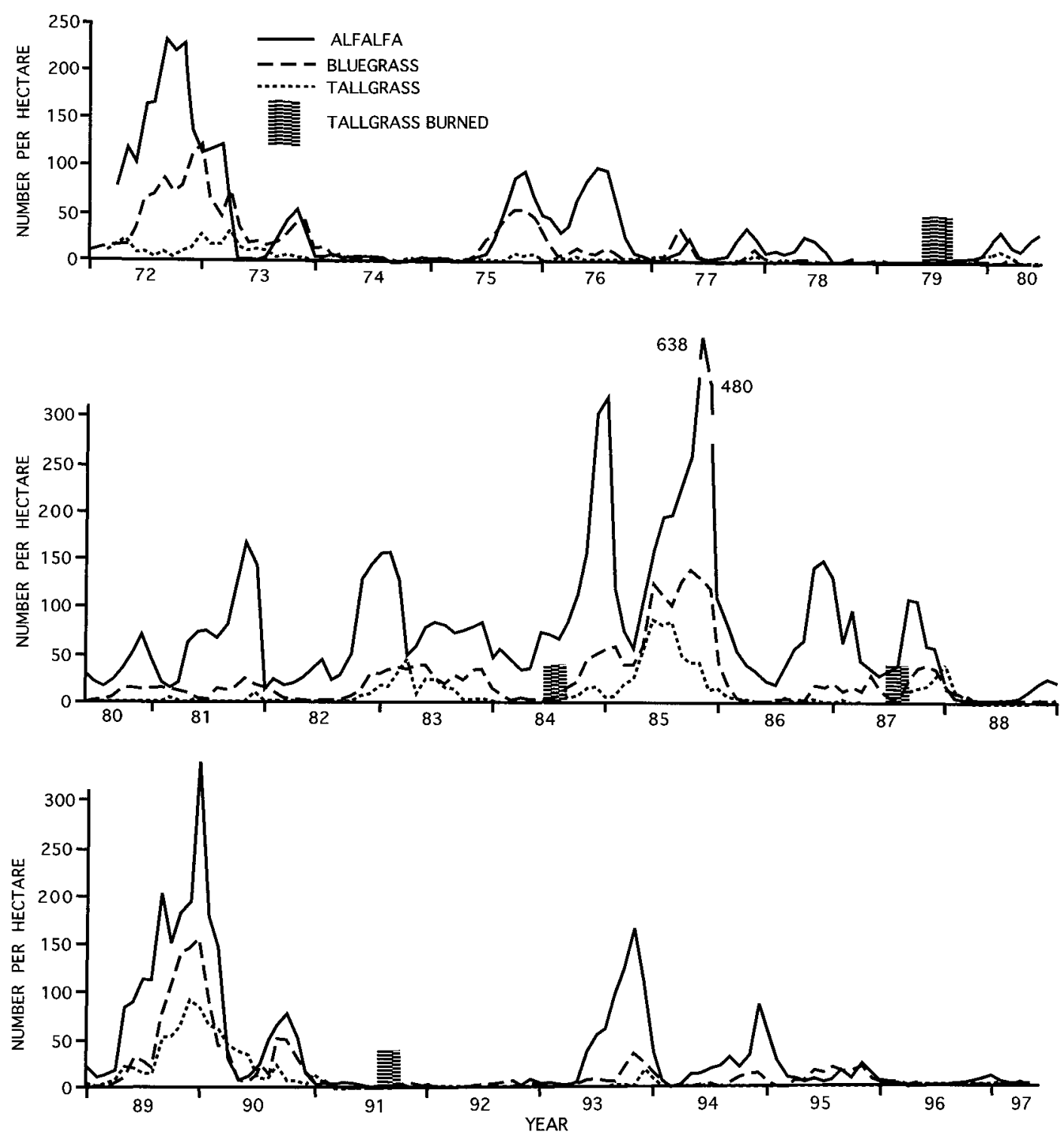

FIG. 2.-Densities of Microtus ochrogaster in 3 habitats in east-central Illinois; populations were monitored at monthly intervals.

of the field had dense vegetation cover at all times. Even in the mown strips, live vegetation and recently mown litter provided dense surface cover.

Trapping was conducted at a 1.0-ha portion of a 2.0-ha, unmown alfalfa field surrounded by cultivated fields, $1.5 \mathrm{~km} \mathrm{~N}$ of the Phillips Tract alfalfa sites, from April through August 1972 as part of another study (Carroll and Getz 1976). Population densities in that site were essentially the same as those in the Phillips Tract site from May through August 1972. Although data from the former site were not used in the analyses, density for April was included (Fig. 2).

Procedures.-All study sites were organized on a grid system with $10-\mathrm{m}$ intervals. One wooden multiple-capture live-trap (Burt 1940) was placed at a station. Each month a 2-day prebaiting period was followed by a 3-day trapping session, except for August 1975-December 
1976 when trapping was conducted at each site every 3 weeks. Cracked corn was used for prebaiting and as bait in traps. We used vegetation or aluminum shields to protect traps from the sun during summer. Wooden traps provided ample insulation in winter so nesting material was not provided in the traps at any time. We estimated trap mortality to be $<0.5 \%$.

Traps were set in the afternoon and checked at about $0800 \mathrm{~h}$ and $1500 \mathrm{~h}$ on the following 3 days. All animals were toe-clipped, $\leq 2$ toes on each foot, at 1 st capture for individual identification. Species, grid station, sex, reproductive condition (males, testes abdominal or descended; females, vulva open or closed, pregnant as determined by palpation, or lactating), and weight to the nearest $1 \mathrm{~g}$ were recorded at each capture.

Density of voles for each trapping session was estimated based on the minimum number known to be alive (MNA-Krebs 1966). Previously marked individuals not captured in a given trapping session, but trapped in a subsequent session, were considered to have been present during sessions in which they were not captured. Although the Jolly-Seber index is recommended for estimating population density (Efford 1992), $\leq 10$ individuals must be trapped each session to obtain reasonable estimates (Pollock et al. 1990). During months that voles were present in the study sites, $\leq 10 \mathrm{M}$. ochrogaster were trapped $26 \%$, $52 \%$, and $62 \%$ of trapping sessions in alfalfa, bluegrass, and tallgrass, respectively. Ten or fewer $M$. pennsylvanicus were trapped during $55 \%$ of sessions in alfalfa, $46 \%$ in bluegrass, and $24 \%$ in tallgrass. Because the same index should be used throughout, we felt justified in using MNA. Further, because we used prebaited multiple-capture live traps checked twice daily for 3 days each session, our capture efficiency was very high. Of animals estimated to be present, $92 \%$ of the M. ochrogaster and $91 \%$ of the $M$. pennsylvanicus actually were captured each session.

Trapping was conducted in the alfalfa and bluegrass study sites in October and late November-early December 1997 and 1998 to detect possible population cycles after termination of the 25-year study. Those trapping sessions followed the protocol described above. Trapping was not conducted at a tallgrass site because October trapping in Trelease Prairie by an ecology class both years yielded very few $M$. ochrogaster.

Data analysis.-Monthly estimates of density for each vole population were not normally distributed, and variances of populations were unequal at the 0.05 level ( $F$-tests-Zar 1999). Because MNA was zero in many cases, data were transformed as $\log (\mathrm{MNA}+1)$ before statistical tests and time series analyses were run. That transformation reduced skewness and kurtosis of all distributions and heterogeneity of variances.

We compared density estimates for the 3 populations of each species by analysis of variance (ANOVA) followed by pairwise Tukey honestly significant difference (HSD) comparisons and density estimates for populations of the 2 vole species in each habitat were compared with 2sample $t$-tests (Zar 1999). Coefficients of variation $(C V)$ were calculated as measures of temporal variability for populations (Zar 1999). Because zeros were included in the analyses, $C V$ actually indicated variability in numbers of animals in a habitat rather than variability of a population (McArdle and Gaston 1993). The standard deviation of the logarithmic transformations of annual densities $(s)$, which has been used as an index of variability for arvicoline rodents (e.g., Henttonen et al. 1985), also was calculated for each population using density estimates for November of each year.

Spectral analysis, using the Fourier decomposition of time series (Bloomfield 1976), was performed to detect cyclicity in the vole populations. We used cross-correlation analysis (CCF plots, SPSS, Inc., Chicago, Illinois) to determine if populations fluctuated in synchrony (Box and Jenkins 1976). That procedure not only calculated the contemporaneous Pearson correlation ( $r$ ) between densities of 2 populations but also compared densities of 2 populations with positive and negative time lags of 1-8 months or more. Cross-correlation plots also were generated to detect possible synchrony or interactions between populations of the 2 species in each habitat.

The criterion for significance for all statistical analyses was $P<0.05$. SYSTAT version 5.2 for the Macintosh (SYSTAT, Inc. 1992) was used for most of the statistical analyses (ANOVA, Tukey, $t$-test, cross-correlation), although the spectral analysis was performed using SYSTAT version 7.0 for Windows (SPSS, Inc. 1997).

Peaks also were identified visually for a sep- 
arate analysis of intervals between population peaks. The minimum density that constituted a population peak was based on the most conspicuous fluctuations occurring in each habitat over the 25 years of the study. For that analysis, we used the following minimum densities to define a population peak for $M$. ochrogaster: alfalfa, 75 voles/ha; bluegrass, 25 voles/ha; tallgrass, 19 voles/ha. Minimum densities of $M$. pennsylvanicus, so determined, to represent peaks were 30 voles/ha in alfalfa and bluegrass; distinct peaks could not be identified in tallgrass. Duration of the trough phases also was determined visually. Those covered the period when the population stabilized at a low density, irrespective of absolute density, after a decline and lasting until the beginning of the next increase phase. Because of small samples, intervals between peaks and duration of troughs were compared among populations by Kruskal-Wallis tests (SYSTAT, Inc. 1992; Zar 1999).

\section{RESULTS}

Microtus ochrogaster.-Mean and maximum population densities of $M$. ochrogaster varied among the 3 habitat types (Fig. 2). A population fluctuation occurred in alfalfa, with a peak of 85 voles/ha in November 1998. The population at the alfalfa site reached a maximum density of 638 voles/ ha (untransformed mean $=50 \pm 4 S E$ voles/ha). The maximum density for the bluegrass habitat was 156 voles/ha $(18 \pm 2$ voles/ha) and that for tallgrass was only 92 voles/ha (7 \pm 1 voles/ha; Fig. 2). Significant heterogeneity was observed among population means $(F=109.9 ;$ d.f. $=2,894$; $P<0.001)$, with Tukey HSD pairwise comparisons indicating that each population was significantly different $(P<0.0001)$ from the other 2 .

Temporal variability was greatest in the tallgrass prairie $(C V=1.2)$, intermediate in bluegrass $(C V=0.8)$, and smallest in alfalfa $(C V=0.6)$. Because standard deviations typically varied positively with means, variability in annual density estimates $(s)$ was highest in alfalfa (0.8), intermediate in bluegrass (0.7), and lowest in tallgrass (0.6).
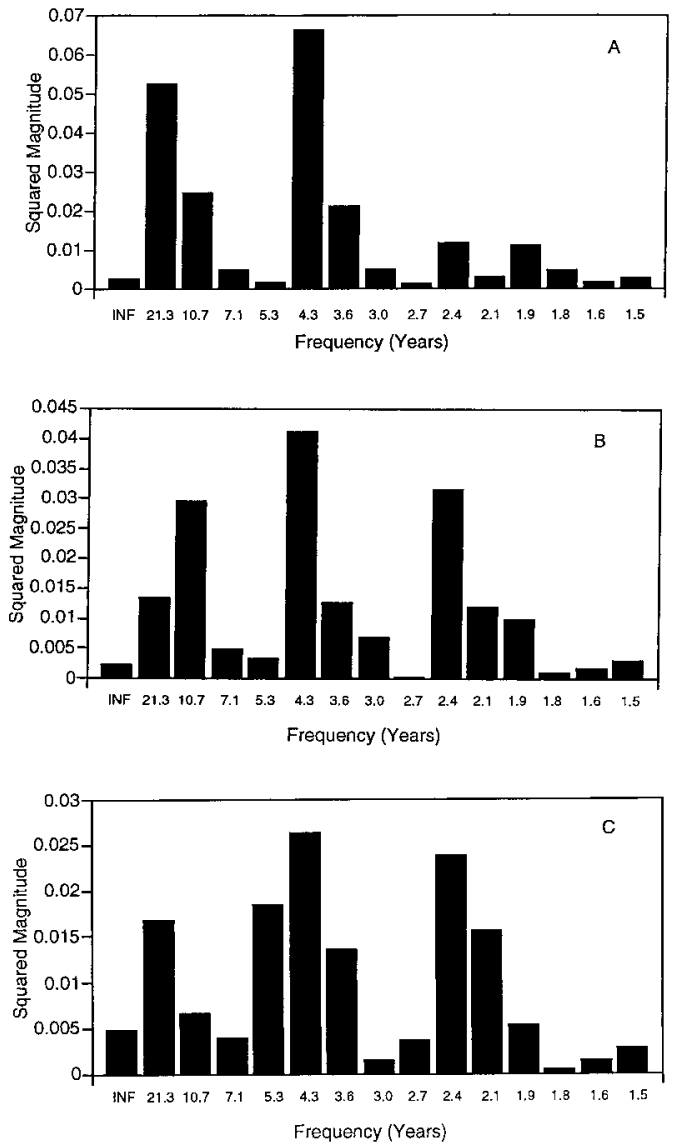

FIG. 3.- Periodgrams produced by time series analysis of density estimates of Microtus ochrogaster in A) alfalfa, B) bluegrass, and C) tallgrass sites; INF = infinity.

Cross-correlation analyses revealed that the 3 populations fluctuated synchronously. We found positive contemporaneous correlations between densities for each pair of populations (alfalfa-bluegrass, $r=0.73$; alfalfa-tallgrass, $r=0.56$; bluegrass-tallgrass, $r=0.70 ; P<0.001)$. Those correlations declined gradually as time lags (positive and negative) were increased.

Spectral analysis produced a periodogram for the alfalfa population (Fig. 3A) that had a dominant frequency of 4.3 years, with a strong secondary peak at 21.3 years. The periodogram for the bluegrass population (Fig. 3B) also showed a primary peak at 4.3 years, but strong secondary peaks oc- 

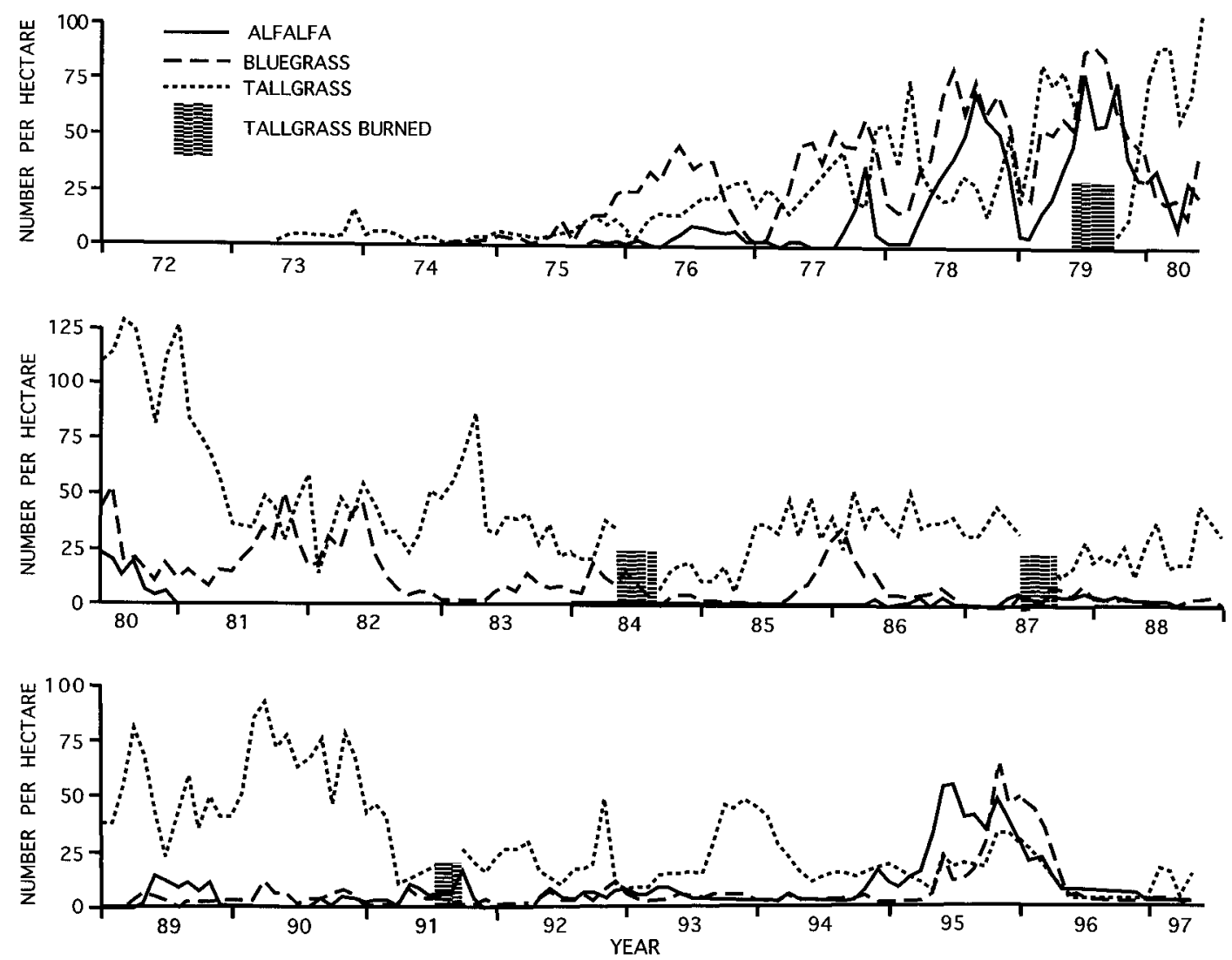

FIG. 4.-Densities of Microtus pennsylvanicus in 3 habitats in east-central Illinois. Populations were monitored at monthly intervals.

curred 2.4 and 10.7 years thereafter. Although the primary peak in tallgrass (Fig. 3C) was 4.3 years, the peak at 2.4 years was nearly as strong; additional strong peaks occurred at 2.1, 3.6, 5.3, and 21.3 years.

Mean interval between peaks of population cycles, as determined from visual inspection of Fig. 2, did not differ among the 3 populations: alfalfa, 24.1 months; bluegrass, 22.7 months; tallgrass, 27.9 months (Kruskal-Wallis $H=0.7, P=0.71$ ).

Although samples were small, duration of the trough phases did not vary among the 3 populations $(H=2.81, P=0.25)$. The tallgrass population had the longest mean (23.8 months) and minimum (10.0 months) durations. Populations in alfalfa and bluegrass had mean durations of 15.5 and 16.7 months, respectively, and a minimum duration of only 2.0 months.

Microtus pennsylvanicus.-Maximum and mean densities of $M$. pennsylvanicus were highest (128 voles/ha and $30 \pm 2$ voles/ha, respectively) in tallgrass, lowest (79 voles/ha and $7 \pm 1$ voles/ha) in alfalfa, and intermediate in bluegrass (91 voles/ha and $14 \pm 1$ voles/ha; Fig. 4). M. pennsylvanicus also displayed a population fluctuation, with a peak of 38 voles/ha in bluegrass in November 1998. Heterogeneity was observed among population means ( $F$ $=107.3 ;$ d.f. $=2$, 807; $P<0.001$ ), and all 3 populations differed (Tukey HSD test; $P$ $<0.001)$. Temporal variability was greatest in alfalfa $(C V=1.2)$, intermediate in bluegrass $(C V=0.8)$, and lowest in tallgrass 
$(C V=0.5)$. The $s$-index was lower in tallgrass (0.5) than in the other 2 habitats (0.6).

Populations occurred only sporadically in alfalfa from 1981 through 1994 and at low densities in bluegrass from 1983 through 1994. During those times, densities in tallgrass remained relatively high (Fig. 4). When densities were high in alfalfa and bluegrass, they sometimes reached levels comparable to those in tallgrass. When data for 1981-1994 were deleted, heterogeneity remained among the 3 populations $(F=$ $13.9 ;$ d.f. $=2$, 249; $P<0.001$ ), but no difference existed between the means of the tallgrass and bluegrass populations (Tukey HSD; $P=0.54)$. The population in alfalfa differed from the other $2(P<0.001)$.

A significant contemporaneous correlation existed only between densities of populations in alfalfa and bluegrass $(r=0.44$, $P<0.001)$. The strength of the correlation between those 2 populations decreased gradually with the introduction of positive and negative time lags. Cross-correlation plots revealed no evidence of synchrony between the population in tallgrass and either population in alfalfa or bluegrass; contemporaneous correlations between those populations did not differ (tallgrass-alfalfa, $r=$ $-0.03, P \approx 0.60$; tallgrass-bluegrass, $r=$ $0.10, P \approx 0.10$ ).

We found little evidence for multiannual population cycles in $M$. pennsylvanicus. Spectral analysis periodograms (Fig. 5) contained a dominant peak at a frequency of 21.3 years for all 3 populations. That was the only strong peak for the population in bluegrass (Fig. 5A). The population in alfalfa had secondary peaks at frequencies of 4.3, 5.3, 7.1, and 10.7 years (Fig. 5B). Secondary peaks for the population in tallgrass occurred at 4.3 and 10.7 years (Fig. 5C).

No visually identifiable multiannual cycle was found in the population in tallgrass; densities seemed to fluctuate erratically. In alfalfa, annual peaks occurred in 1977, 1978, and 1979, with intervals of 10 and 11 months between peaks; the species was present sporadically until reaching another
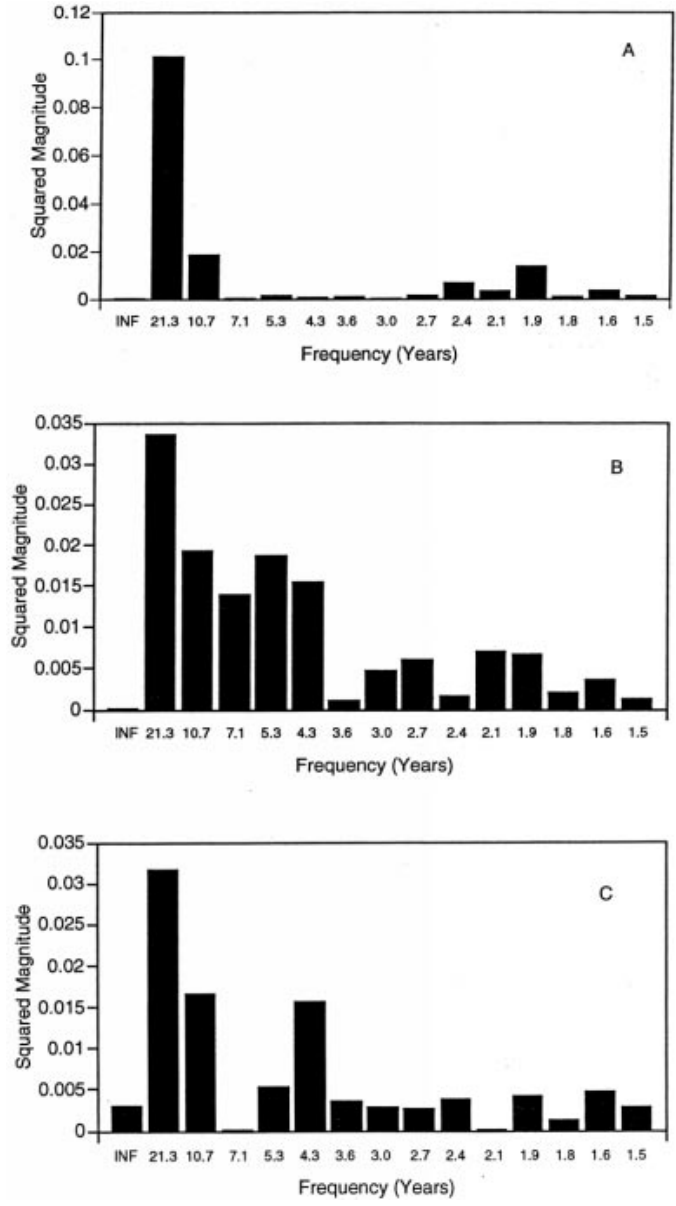

FIG. 5.-Periodgrams produced by time series analysis of the density estimates of Microtus pennsylvanicus in A) alfalfa, B) bluegrass, and C) tallgrass sites; INF = infinity

peak in 1995. The population in bluegrass seemed to display annual cycles from 1976 through 1982, with intervals of 7-17 months between peaks. Density then remained at low levels until peaks in 1986, 1995, and 1998. Peak densities during the annual cycles did not occur at the same time of the year (June, July, August, and November); the 3 later peaks occurred during February (1986) and November-December (1995 and 1998). From 1976 through 1982, the trough phase typically lasted only 2 or 3 months; 1 trough lasted 6 months (Fig. 4). 
Interspecific comparisons.-Mean density of $M$. ochrogaster was higher than that of $M$. pennsylvanicus in alfalfa $(t=14.53$, d.f. $=556, P<0.001)$ and lower in tallgrass $(t=-15.35$, d.f. $=566, P<0.001)$. We found no difference in mean densities of the 2 species in bluegrass $(t=1.12, d$.f. $=575, P=0.26)$. Maximum density of $M$. ochrogaster recorded in tallgrass (92 voles/ ha) was less than that of $M$. pennsylvanicus (128 voles/ha), but maximum densities of M. ochrogaster in both alfalfa (638 voles/ ha) and bluegrass (156 voles/ha) were higher than those recorded for $M$. pennsylvanicus (79 voles/ha and 91 voles/ha, respectively; Figs. 2 and 4).

Cross-correlation analysis revealed no evidence of synchrony between population fluctuations of the 2 species in any of the 3 habitats. In alfalfa, where densities of $M$. ochrogaster reached very high levels and densities of $M$. pennsylvanicus were typically low, we found a significant negative correlation between densities of the 2 species (contemporaneous $r=-0.34, P<$ $0.001)$ that persisted for positive and negative time lags of 12 months. In tallgrass, the contemporaneous correlation between densities of the 2 species was significant $(r$ $=0.19, P \approx 0.001$ ); however, the correlation was even stronger for densities of $M$. ochrogaster and $M$. pennsylvanicus 2-7 months earlier. In bluegrass, the contemporaneous correlation between densities of M. ochrogaster and $M$. pennsylvanicus was not significant ( $r=-0.05, P \approx 0.40$ ). However, the cross-correlation plot revealed significant negative correlations of $M$. ochrogaster with $M$. pennsylvanicus densities $>2$ months earlier; correlations were strongest for $M$. pennsylvanicus densities 4-10 months earlier.

\section{DISCUSSION}

Synchronous multiannual population cycles of $M$. ochrogaster were apparent in bluegrass and alfalfa habitats. Although the mean interval between peaks was about 2 years, intervals were highly variable (8-64 months). Spectral analysis indicated a primary peak at a 4.3-year interval in both habitats, suggesting the 3- to 4-year population cycle typically ascribed to voles. A strong secondary peak at 21.3 years for the population in alfalfa most likely resulted from the influence of very high peak densities in 1985.

Because of generally very low population densities and low peaks during population fluctuations, cycles in $M$. ochrogaster were not clearly discernible from visual inspection of data from tallgrass sites. However, except for 1995, even the small amplitude peaks in tallgrass appeared synchronous with the more obvious peaks in alfalfa and bluegrass. Spectral analysis revealed that the data were not fit by a single waveform, in effect indicating no distinct population cycle in this habitat. Only through cross-correlations of population fluctuations in tallgrass with those in alfalfa and bluegrass could we discern an indication of a possible multiannual population cycle in tallgrass.

Unlike M. ochrogaster, M. pennsylvanicus displayed no evidence of multiannual population fluctuations in its most favored high cover habitat, tallgrass (Birney et al. 1976), whether determined by visual inspection or spectral analysis. The $s$-index for that habitat was only 0.5. Population fluctuations in alfalfa and bluegrass were either annual or erratic.

Despite the propensity for dispersal by M. pennsylvanicus (Christian 1970), this species exhibited no consistent synchrony in population fluctuations among the $3 \mathrm{hab}-$ itats. Although annual fluctuations occurred in alfalfa and bluegrass during 1977, 1978, 1979, and 1995, we observed no fluctuations in alfalfa corresponding to the bluegrass fluctuations in 1982, 1983, 1985, and 1998.

Henttonen et al. (1985) found that $s$, the standard deviation of logarithmic transformations of autumn densities, could be used to discriminate between cyclic and noncyclic populations of Clethrionomys in Fen- 
noscandia. Cycling populations in that region had $s$-indices $>0.5$ and $s$-values of noncycling populations were $<0.5$. However, Saitoh et al. (1998) found no such relationship between $s$ and cyclicity among populations of Clethrionomys rufocanus in Japan. In our study, values of $s$ were $\geq 0.5$ for all populations, even though spectral analysis suggested no pattern of multiannual fluctuations for $M$. pennsylvanicus. Therefore, $s$ was not an indicator of cyclicity for vole populations in central Illinois.

Manipulations required to retard successional changes in the 3 habitats (mowing in alfalfa and bluegrass, burning in tallgrass) had no apparent effect on population fluctuations of either vole. The alfalfa sites were mowed in the same pattern throughout each summer of the study. Thus, manipulative effects were similar each year. We observed no changes in vole densities associated with mowing in alfalfa sites. The mowing protocol in bluegrass retained dense cover of bluegrass and did not disturb food availability. We also observed no changes in numbers of voles related to mowing in bluegrass. Burning of tallgrass sites during spring eliminated all cover and food. Populations of both species disappeared from sites upon burning. Voles did not recolonize tallgrass sites until the following September or October. However, no long-term disruption of population trends of either species related to the burning regime was apparent (Figs. 2 and 4).

Batzli (1992) indicated that it is difficult to separate effects of vegetative cover and food availability on demography of arvicoline rodents. Where such discrimination has been possible, food seems to be of overriding importance (Batzli 1992; Batzli and Lesieutre 1991; Batzli et al. 1983; Cole and Batzli 1979).

Comparisons of population fluctuations of $M$. ochrogaster in the 3 habitat types suggest that occurrence of population cycles is tied to food availability rather than to cover. Multiannual cycles were most distinct, as perceived visually and by spectral analysis, in the habitat with highest quality food, alfalfa (Cole and Batzli 1979). That habitat provided the least permanent cover of the 3; cover was especially low during winter and early spring. The population in the intermediate food habitat, bluegrass, which had moderately dense year-round cover, displayed intermediate-amplitude fluctuations and a periodogram with several strong peaks. The population in tallgrass, occupying a site with very low food availability but very dense year-round cover, had exceptionally low barely discernible population fluctuations and a periodogram that displayed 6 strong peaks from 1.2 to 21.3 years.

Populations of $M$. pennsylvanicus seemed to be influenced more by vegetative cover than food availability with respect to abundance and peak densities achieved. Typically, the species was most abundant and displayed highest peak densities where cover was greatest but where preferred food availability was lowest (i.e., tallgrass). Intermediate densities occurred in bluegrass where cover and preferred food were intermediate. Lowest densities were recorded in alfalfa, which provided very high food availability but relatively sparse cover. Also, food resources for M. pennsylvanicus possibly were adequate in all 3 habitats. Although $M$. pennsylvanicus preferentially selects succulent forbs, it does well when only grasses are available (Lindroth and Batzli 1984; Marquis and Batzli 1989). Even if food was adequate in all 3 habitats, tallgrass would still be the highest quality habitat of the 3 because of its greater yearround cover. Cover remains the more important factor with respect to success of populations of $M$. pennsylvanicus.

Analyses of the 25-year data sets from the 3 habitat types thus show among-habitat differences in demography of the 2 species and between-species differences in the same habitats. Only $M$. ochrogaster displayed evidence of a 3- to 4-year population cycle. Taitt and Krebs (1985) summarized published accounts of population fluctua- 
tions in M. ochrogaster and M. pennsylvanicus. Both species were recorded as displaying annual and multiannual population cycles at different times at the same site and at the same time at adjacent sites. In other studies, populations of the 2 species fluctuated in synchrony at adjacent sites but not at the same site (Taitt and Krebs 1985).

In our study, mean densities, maximum observed densities, and presence of multiannual cycles of $M$. ochrogaster seemed to be influenced more by food than by cover. In contrast, mean densities and maximum recorded densities of $M$. pennsylvanicus were affected more by cover than food availability. However, M. pennsylvanicus displayed no evidence of multiannual fluctuations in any of the 3 habitats, including those with dense cover.

Analysis of our results demonstrates that annual and multiannual population cycles are not necessarily associated with habitat quality. M. ochrogaster displayed multiannual population cycles in marginal and high-quality habitats. M. pennsylvanicus did not display distinct annual or multiannual fluctuations in either high-quality or marginal habitats.

\section{ACKNOWLEDGMENTS}

The study was supported in part by the National Science Foundation (DEB 78-25864), the National Institute of Health (HD 09328), and the University of Illinois School of Life Sciences and Graduate College Research Board. We thank the following for their assistance with the field work: L. Verner, R. Cole, B. Klatt, R. Lindroth, D. Tazik, P. Mankin, T. Pizzuto, M. Snarski, S. Buck, K. Gubista, S. Vanthernout, M. Schmierbach, D. Avalos, L. Schiller, J. Edgington, B. Frase, and the 1,063 undergraduate "mouseketeers" without whose extra hands in the field the study would not have been possible. C. Haun, M. Thompson, and M. Snarski entered data sets the computer.

\section{Literature Cited}

Agrell, J., S. Erlinge, J. Nelson, And M. Sandell. 1992. Body weight and population dynamics: cyclic demography in a non-cyclic population of the field vole (Microtus agrestis). Canadian Journal of Zoology 70:494-501.

BATZLI, G. O. 1992. Dynamics of small mammal populations: a review. Pp. 831-850 in Wildlife 2001: populations (D. R. McCullough and R. H. Barrett, eds.). Elsevier Applied Science, New York.

BAtzli, G. O. 1996. Population cycles revisited. Trends in Ecology and Evolution 11:448-489.

Batzli, G. O., And C. Lesieutre. 1991. The influence of high quality food on habitat use of arctic microtine rodents. Oikos 60:299-306.

Batzli, G. O., F. A. Pitelka, and G. W. Cameron. 1983. Habitat use by lemmings near Barrow, Alaska. Holarctic Ecology 6:255-262.

Birney, E. C., W. E. Grant, And D. D. Baird. 1976. Importance of vegetative cover to cycles of Microtus populations. Ecology 57:1043-1051.

Buornstad, O. N., N. C. Stenseth, T. Saitoh, and O. C. LingJAERDE. 1998. Mapping the regional transition to cyclicity in Clethrionomys rufocanus: spectral densities and functional data analysis. Research in Population Ecology 40:77-84.

BLOOMFIELD, P. 1976. Fourier analysis of time series: an introduction. John Wiley \& Sons, New York.

Box, G. E. P., AND G. M. Jenkins. 1976. Time series analysis: forecasting and control. Revised ed. Holden-Day, San Francisco, California.

BURT, W. H. 1940. Territorial behavior and populations of some small mammals in southern Michigan. University Michigan Museum of Zoology Miscellaneous Publications 45:1-58.

Carroll, D., AND L. L. Getz. 1976. Runway use and population density in Microtus ochrogaster. Journal of Mammalogy 57:772-776.

Christian, J. J. 1970. Social subordination, population density, and mammalian evolution. Science 168:8490.

Cole, F. R., And G. O. Batzli. 1979. Nutrition and population dynamics of the prairie vole, Microtus ochrogaster, in central Illinois. The Journal of Animal Ecology 48:455-470.

EFFord, M. 1992. Comment-revised estimates of the bias in 'minimum number alive' estimator. Canadian Journal of Zoology 70:628-631.

Getz, L. L., F. R. Cole, AND D. L. Gates. 1978. Interstate roadsides as dispersal routes for Microtus pennsylvanicus. Journal of Mammalogy 59:208212.

Getz, L. L., F. R. Cole, L. Verner, J. E. Hofmann, AND D. Avalos. 1979. Comparisons of population demography of Microtus ochrogaster and M. pennsylvanicus. Acta Theriologica 24:319-349.

GetZ, L. L., AND J. E. Hofmann. 1999. Diversity and stability of small mammals in tallgrass prairie habitat in central Illinois, USA. Oikos 85:356-363.

Getz, L. L., J. E. Hofmann, B. J. Klatt, L. Verner, F. R. Cole, AND R. L. Lindroth. 1987. Fourteen years of population fluctuations of Microtus ochrogaster and M. pennsylvanicus in east central Illinois. Canadian Journal of Zoology 65:1317-1325.

Henttonen, H., A. D. McGuire, and L. Hansson. 1985. Comparison of amplitudes and frequencies (spectral analyses) of density variation in long-term data sets of Clethrionomys species. Annales Zoologici Fennici 22:221-227. 
Krebs, C. J. 1966. Demographic changes in fluctuating populations of Microtus californicus. Ecological Monographs 36:239-273.

Krebs, C. J., B. L. Keller, AND R. H. TAmarin. 1969. Microtus population biology: demographic changes in fluctuating populations of $M$. ochrogaster and $M$. pennsylvanicus in southern Indiana. Ecology 50: 587-607.

Krebs, C. J., AND J. A. Myers. 1974. Population cycles in small mammals. Advances in Ecological Research 8:267-399.

LindROTH, R. L., AND G. O. BATZLI. 1984. Food habits of the meadow vole (Microtus pennsylvanicus) in bluegrass and prairie habitats. Journal of Mammalogy 65:600-606.

Marcstrom, V., N. Hoglund, and C. J. Krebs. 1990. Periodic fluctuations in small mammals at Boda, Sweden from 1961-1988. The Journal of Animal Ecology 59:753-761.

MARQuis, R. J., AND G. O. BAtZLI. 1989. Influence of chemical factors on palatability of forage to voles. Journal of Mammalogy 70:503-511.

McArdle, B., And K. Gaston. 1993. The temporal variability of populations. Oikos 67:187-191.
Pollock, K. H., J. D. Nichols, C. Brownie, And J. E. BROWNIE. 1990. Statistical inference for capture-recapture experiments. Wildlife Monographs 107:197.

Saitoh, T., N. C. Stenseth, and O. N. BJornsta. 1998. The population dynamics of the vole Clethrionomys rufocanus in Hokkaido, Japan. Research in Population Ecology 40:61-76.

SPSS, INC. 1997. SYSTAT 7.0 for Windows: statistics. SPSS, Inc., Chicago, Illinois.

SYSTAT, INC. 1992. SYSTAT: statistics, version 5.2. SYSTAT, Inc., Evanston, Illinois.

TAitT, M. J., AND C. J. Krebs. 1985. Population dynamics and cycles. Pp. 567-620 in Biology of New World Microtus (R. H. Tamarin, ed.). Special Publication, American Society of Mammalogists 8:1893.

ZAR, J. H. 1999. Biostatistical analysis. 4th ed. Prentice Hall, Upper Saddle River, New Jersey.

Submitted 6 December 1999. Accepted 5 June 2000.

Associate Editor was Ronald E. Barry. 